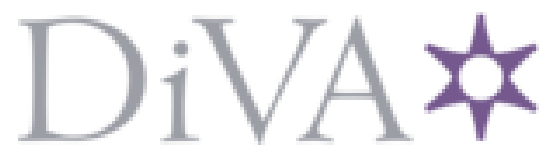

http://www.diva-portal.org

This is the published version of a paper presented at Proceedings of the Second Workshop on Computing within Limits.

Citation for the original published paper:

Pargman, D., Eriksson, E., Friday, A. (2016)

Limits to the Sharing Economy.

In: ACM Digital Library

http://dx.doi.org/10.1145/2926676.2926683

N.B. When citing this work, cite the original published paper.

Permanent link to this version:

http://urn.kb.se/resolve?urn=urn:nbn:se:kth:diva-196932 


\section{Limits to the Sharing Economy}

\author{
Daniel Pargman, Elina Eriksson \\ KTH Royal Institute of Technology \\ Stockholm, Sweden \\ \{pargman,elina\}@kth.se
}

\author{
Adrian Friday \\ Lancaster University \\ Bailrigg, LA1 4YW, United Kingdom \\ a.friday@lancaster.ac.uk
}

\begin{abstract}
There has been much interest in the Sharing Economy in recent years, accompanied with the hope that it will change and specifically make better use of existing resources. It intuitively makes sense, from a sustainability point of view, that the sharing of resources is good. It could even be said that the Sharing Economy ought to align well with Computing within Limits and its underlying premises. In this paper however, we take a critical stance and will elaborate on the intersection between the Sharing Economy and Limits (including pinpointing potential conflicts) so as to identify and discuss a 'Limits-compliant Sharing Economy'. We argue that even though there are limits to the Sharing Economy today, it still has potential benefits for a future of scarcitybut only if the practice of sharing is approached with a dual focus on sharing and on limits at the same time. Finally we conclude that even though we have begun to explore the future of sharing, there is still a need to further develop ideas of how the underlying infrastructure for this movement will look.
\end{abstract}

\section{CCS Concepts}

-Social and professional topics $\rightarrow$ Sustainability;

\section{Keywords}

Computing within Limits; Sharing Economy; Collaborative Consumption; Sustainability

\section{INTRODUCTION}

There has been much talk about "the Sharing Economy" in the last few years, with high hope that it will help promote sustainability due to the simple fact is that it makes sense, from a sustainability point of view, to share resources. This is especially true in the case of resources that have a high "idling capacity", i.e. resources that are both expensive and seldom used (like a car, an expensive kayak or a summer cottage).

Permission to make digital or hard copies of all or part of this work for personal or classroom use is granted without fee provided that copies are not made or distributed for profit or commercial advantage and that copies bear this notice and the full citation on the first page. Copyrights for components of this work owned by others than the author(s) must be honored. Abstracting with credit is permitted. To copy otherwise, or republish, to post on servers or to redistribute to lists, requires prior specific permission and/or a fee. Request permissions from permissions@ acm.org.

LIMITS '16, June 08 - 10, 2016, Irvine, CA, USA

(C) 2016 Copyright held by the owner/author(s). Publication rights licensed to ACM. ISBN 978-1-4503-4260-5/16/06 . .\$15.00

DOI: http://dx.doi.org/10.1145/2926676.2926683
While the Sharing Economy refers to a dizzying array of practices that might be more sustainable than current individualistic alternatives, Computing within Limits instead refers to absolute limits in our use of physical resources (material, energy etc.) but without tying these limits to a particular set of practices (sharing or otherwise).

Computing within Limits also assumes an end to the exponential growth of more or less every possible performance measure in the computing industry during the last 50 years, that even at the most basic level, has been predicated on an abundance of natural resources; an expanding industrial base; and on exponential economic growth. These foundations (abundant resources, expanding industrial base, further exponential economic growth) will not be maintained in the coming decades; rather we will encounter a number of different (linked) biophysical limits.

This line of thought strongly implies that we are currently living beyond our means and that a series of voluntary or involuntary "corrections" are inevitable in all areas of human endeavour (including computing) during the 21st century. An increase of sharing (of various resources) could be one such correction. Consequently, it would seem that there should be a natural fit between the ideas and the practices that constitutes the Sharing Economy on the one hand, and on the ideas behind Computing within Limits on the other, i.e. there clearly are absolute limits that the planet Earth imposes upon us.

In this paper we reject this simple intuitive mapping. It is not that the mapping is wrong, but it is too simplistic and one-sided. While the Sharing Economy and Computing within Limits ("Limits" from here on) can overlap and pull in the same direction, it is also possible to conceive of situations where these two perspectives contradict one another and might even pull in different or opposing directions. The contribution of this short paper is firstly to examine and analyse this possible intersection between the Sharing Economy and Limits (including identifying potential conflicts) and secondly to identify and briefly discuss issues of importance for a Limits-compliant Sharing Economy. What could a sharing economy for a future of limitations look like?

\section{SHARING ECONOMY}

The concept and the term "the Sharing Economy" gained popularity in the wake of the publication of Rachel Botsman and Roo Roger's 5] book "What is mine is (y)ours: The rise of collaborative consumption" as well as a slew of texts in the popular and business press. A lot of inspiration originally came from the proven ease of sharing resources online 
and the popularity of phenomena such as "open source software", "social peer-to-peer processes" and "commons-based peer production". Because of the non-rival (or rather "nonsubtractable") nature of information [12, it is possible to share digital resources without diminishing the value of the resource for the original owner. In fact, it can even be argued that information becomes more rather than less valuable the more people have access to it. With inspiration from the digital world, it became possible to imagine that also a variety of physical resources (including physical space) could be better utilized and shared with the help of inexpensive digital tools and platforms to help facilitate the necessary coordination.

Broadly speaking the Sharing Economy, sometimes referred to also as "collaborative consumption", can be categorised as the: "recirculation of goods, increased utilization of durable assets, exchange of services, and sharing of productive assets" [32, p. 2]. There is little actual consensus in the use of the term "the Sharing Economy": it has come to mean different things to different people. For example, some choose to define sharing narrowly and specifically exclude renting and leasing 2], while others are open to a wider interpretation that includes commercial sharing (product service systems) 20]. The differing meanings that the term Sharing Economy has taken on might very be an effect of nascent developments rather than an inherent fuzziness in the concept.

Some argue that this perspective does not go far enough and that the future of the Sharing Economy lies in integrating it with Circular Economy thoughts and concepts 7 , 39]. This includes fundamental critique of the contemporary societal structures and business models that contain much "structural waste". This perspective emphasises that better utilization of a car, be it the case that it is both expensive and seldom used, does not go far enough. A more fundamental problem is that a car-however many share it - and the whole transport system that has been constructed around the car embody significant structural waste. While most cars are idle for more than 90 or $95 \%$ of the time - something that the Sharing Economy can "fix" - the more fundamental contradiction is that we build and propel 1500 kilos of metal to haul around (typically) one human that weighs 70 kilos, and, this is not the only contradiction of a transportation system that is built on individual car ownership. Circular Economy proponents claim that we should concentrate not on the problem of better utilizing the car, but on how develop regulations, incentives and business models that shift the focus from access to a specific physical resource (the car), to providing the service of "mobility", and, with a focus on value creation and (radical) new business models.

We acknowledge this perspective, but in this paper we focus on using the term "the Sharing Economy" to refer to the practice of making use of underutilized physical resources that had previously been neglected by using computer systems as a mediator. For us, the sharing may be between peers, between commercial actors and citizens, or between public actors and citizens. Common to all, the resources in question might be available at different times and the cost of coordination is radically decreased through the use of ICT [33. For the most part, we concentrate on the sharing of physical resources as this aligns well with the focus on limited physical resources found in Limits to computing.

Ecological sustainability has often been hailed as the main argument for promoting or participating in the Sharing Economy [18. As mentioned, it makes sense to share expensive resources rather than for everyone to have "one of their own". In a Swedish context, it makes sense for neighbours on a suburban street to have a access to a snowblower rather than for each neighbour to own his or her own. A snowblower is expensive, takes up a lot of space in a garage and is of limited use for most of the year. Some years there is not enough snow to make them useful at all. Ecologically speaking, access instead of ownership thus seems both sensible and resource efficient. Botsman and Rogers 5. claim that the average US power drill is used only for 15 minutes during its lifetime - and what people really want is a hole in the wall (access), not the drill itself (ownership).

The other two major arguments in favor of sharing are social and economical. Sharing encourages, or forces you to interact and network with other. Successfully sharing resources can be seen as a way to build up capital and generalized trust 27,28 . For people with limited financial means, the difference between sharing and not sharing can be not just inconvenience but rather non-access. The concordant argument is that people with less financial resources might still own something (an extra room, an idle car) that can have economic value in the Sharing Economy 8.

The economic argument implies that sharing ought to be comparatively attractive in societal strata with less economic resources and in less affluent societies [10, 35]. It might however in some cases, despite the obvious need, be harder for people with less resources and less "slack" to trust strangers. This could help explain why the Sharing Economy phenomena currently is largely a middle-class phenomenon. The Sharing Economy has also received its fair share of criticism 1]. The term "we-washing" 15] has been used in much the same way that "greenwashing" is used; to refer to practices that are supposedly environmentally or socially beneficial while in reality referring to nothing much but a strategic use of language that sanitises deeply problematic practices. The Sharing Economy has also been accused of being complicit in the 'precariatization' of labor 36] and has been referred to as the "on-demand" or the "gig" economy [21].

While the two most prominent poster children of the Sharing Economy, Über and Airbnb, have a market capitalization that is astronomical, it can at times be difficult to see the difference between these two companies and other big corporations that are highly valued, have external investors in whose interest it is to maximize the returns on their investments, and, who make their profits on the backs of a large number employees or non-employed "collaborators" (service providers). While these giant companies - the Sharing Economy superstars that have been featured in innumerable new articles - do make underutilized resources more widely available, they do so at a high price by cynically evading costs that more traditional competitors are liable for, such as workers' pensions, workers' health benefits, employees' minimum income, ensuring safe working conditions etc. Despite being housed under the same (Sharing Economy) umbrella, these companies are worlds away from small-scale, bottom up, non-exploitative, non-profit initiatives such as various experiments with community-supported agriculture (CSA), timebanking, freecycling, skillsharing etc. 3, 9

\section{SHARING SUSTAINABLY}

There are, from a sustainability point of view, obvious 
ways that the Sharing Economy and Limits can be aligned with regards to the environmental impact of our use of resources. It is possible to intensify the use of a specific resource, or to prolong its lifespan through participation in the Sharing Economy and by means of selling, renting, borrowing, swapping, sharing or gifting. There does however exist substantial critique of the claimed environmental benefits, mainly due to a dearth of empirical studies of the environmental impact of sharing initiatives 32. It is thus an open question of how well the Sharing Economy and Limits actually align. Limits implicitly assumes a shift from a growth economy to either a steady-state or a degrowth economy sometime in the next few decades. It is very easy to imagine an alignment between a decrease in our use of resources (e.g. us buying less stuff) and a corresponding increase in sharing practices in order to maintain our standards of living while using less money. It is however also easy to imagine that there are various problematic rebound effects of the Sharing Economy 30 as we illustrate using two examples:

1. Airbnb has often been hailed as a Sharing Economy success story because what could be better than to offer up idle space (an extra guest room or an unused summer cottage) instead of building new hotel complexes? There are however several rebound effects that threaten to reduce or annul the hoped-for resource savings. The first is that by making it easy and inexpensive to find lodging (increase in efficiency of finding lodging), we could in fact increase the carbon footprint due to a lockstep increase of weekend trips, tourism and "frivolous" (air) travel (i.e. incur rebound effects). In many cities it has even become more profitable to rent out apartments to temporary visitors through Airbnb than to rent the apartment to someone who lives and works in the city. The increased popularity of Airbnb has thus taken apartments off the ordinary housing markets - a very different notion to renting out "surplus" space.

2. The availability and the ease of establishing second hand markets, for example in the form of craigslist, could lead to higher rather than lower levels of consumption. Increased efficiency of second hand markets in combination with a lack of absolute limits leads to a decrease of prices and an increase in consumption 16 . 24, as easy and convenient second-hand markets can "leverage" goods to those with fewer economic means. One example is the first author's son who at the age of 11 (Spring 2015) had saved just enough money to buy a second-hand iPhone 5c for USD 350. The seller had just bought a brand new iPhone 6 and the asking price of his not-very-old iPhone $5 \mathrm{c}$ was within the means of an 11 year old who would not have been able to buy a similar brand new phone. It might also be the case that the seller would not have been able to buy his iPhone 6 without the "subsidy" that came from selling his previous phone. There is here thus a direct misalignment between the Sharing Economy and a Limits perspective. Since there are no inherent limits to the absolute size of the Sharing Economy, it can in fact grow the market for consumption.

Both these examples can better be understood by way of Hilty's 13 argument about sufficiency (e.g. absolute limits) in relation to efficiency. Hilty's call to arms is " $n o$ efficiency without sufficiency" lest we risk running up against various dreaded rebound effects [30]. This suggests that the Sharing Economy will only be environmentally sound when it is contained within absolute limits.

To summarise, the Sharing Economy holds a great potentialto help do more with less - and to live lives of relative material comfort despite a decrease in our overall use of energy and natural resources (and a lower economic standard of living). However, such an outcome is by no means guaranteed, since the sharing economy could equally well (but counterintuitively) become aligned with, and further fuel the current consumerist culture. It is not enough to simply endorse the Sharing Economy, and instead of keeping our eyes on the one ball (the Sharing Economy), we need to keep our eyes on two balls at the same time (the Sharing Economy and Limits).

We can compare this with the Transition Town (TT) Movement's relationship to the twin challenges of peak oil and climate change 14. Hopkins argues that if you regard either of these two problems separately, you might arrive at solutions that will "solve" (e.g. alleviate) one problem while failing to solve - or even exacerbating - the other. A solution to peak oil (energy shortages) that does not take climate change into account might suggest that we should relax regulations around drilling, or expand our coal-to-liquids industrial capacity in order to make up for oil shortages. Focusing (only) on climate change might similarly emphasize solutions that assume we will continue to have access to huge quantities of inexpensive energy. The Transition Town solution is instead to "look at peak oil and climate change as two intertwined problems" [14, p. 38], or, as two aspects of the same underlying problem. Transition Town solutions should therefore strive to both build (energy) resilience and to cut carbon emissions at the same time. Our goal here is to analogously suggest Sharing Economy solutions that are "Limits-compliant", e.g. that take absolute limits into account.

Limits-compliant sharing can potentially help support a society operating within absolute limits by squeezing more from less: more efficiency, less wasted capacity, less wasted journeys, more sharing of space, expensive goods, resources, food etc. This would ideally then be brought about by better coordination, planning and sharing and supported by (simple, resource-stingy, modular) ICT platforms. These ICT platforms themselves will naturally also have to respect and operate in the face of limits and we turn to this question below. A methodological problem both for this paper and more generally is that it is difficult to fully outline a Limitscompliant Sharing Economy without first having outlined the future of computing in a world of limits, but this goes beyond the scope of this paper.

\section{A LIMITED INFRASTRUCTURE FOR SHARING}

One key factor that makes the Sharing Economy interesting from a Computing within Limits perspective is the fact that the current revival of sharing and collaborative consumption is mediated and arguably driven by the drastically shrinking marginal cost of using various online platforms to coordinate these activities 33. These platforms can be custom built, customizable or piggyback on already 
existing communication channels and social networks such as Facebook. While the prototypical Sharing Economy platform would be a public library, computer-mediated platforms have made it easy to scale up sharing in terms of size, numbers and reach; mediated forms of sharing encompass the sharing of resources with people who might be strangers and thus reaches far beyond traditional forms of resource sharing within a family, a neighbourhood or a community (socio-cultural sharing) 20.

The computer resources (including Sharing Economy platforms) that we will have access to in the future might - from a limits perspective - be vastly different from today's. The sharing economy is in some sense predicated on convenient globally available channels of communication, for media exchange, and of course, payment. While the data intensity of these transactions might be small in comparison to, say, streaming digital media; they leverage the same highly available cloud infrastructures. It is worth remembering that the cloud is highly energy intensive and growing in energy and environmental impacts, despite ongoing computational efficiency improvements. The cloud is estimated to grow to over 1,000 TWh, equivalent to the combined annual energy demand of Japan and Germany taken together, within a decade 22]. This observation leads to a couple of questions that ought to be answered through inquiries within the field of Computing within Limits.

First of all, what is it that has made the Sharing Economy take off during the last five years instead of, say, 10 or 20 years ago? It can be argued that current trends constitute a continuation of, rather than a break with previous trends. The classified ads website craigslist has, after all, existed since 1995 (at that time as a local email distribution list). We however argue that current developments represent something more than just an extrapolation of previous trends. Using the terminology from Rogers' classic "Diffusion of Innovations" 31, we believe that as Sharing Economy ideas and practices has started to reach the mainstream culture, the Sharing Economy is moving from only involving "innovators" and "early adopters" to the much larger group "early majority". The answer to the question "why now?" will thus partly be dependent on aspects far outside of the digital technologies themselves, but are there also inherent aspects of contemporary computer systems that come into play and that has contributed to current success of various Sharing Economy services? Could the recent interest in and success of such platforms be connected to, for example, mass participation on the Internet, the web 2.0 interactional styles, the general availability of mobile devices and mobile broadband? If so, could the Sharing Economy continue to thrive also in a world of less (affordable and available) computational power, less bandwidth and simpler user interfaces?

Users of these services expect access at all times, but looking at a future of scarcity, might the large scale social networks and globally available servers even be possible? It seems reasonable to assume that energy will itself be more limited: if we are fortunate enough to fully develop and support renewable energy programmes 17], then future energy grids will have very different characteristics to those we (in the first world at least) enjoy today. The capacity of the energy grid will vary much more with the seasons and during the day as renewables and demand ebb and flow. There will be times when there is insufficient capacity, and the poten- tial for periodic brownouts or blackouts 26]. Using stores of energy, and making the most of energy as a limited resource when it is available (and being robust to when it isn't) will be a new paradigm 37, particularly for energy dependent devices such as computers and networks, and their associated software.

The infrastructure that emerges may be more closely related to an earlier (even pre-web) Internet, with more localised and smaller scale parts of the sharing platform (analogous to 'bulletin boards') operating independently with more reliance on asynchronous messaging and loose synchronisation. This will certainly change the user experience of the Internet, and will likely be equally disruptive to the revenue streams and payment systems that currently sustain them. Will payment, trust and reputation profiling services currently offered by global banks and well-known brands and corporations survive this shift? Or will new, perhaps decentralised, alternatives need to emerge? Just as "responsive design" will adapt presentation of a webpage so that it seamlessly detects and adapts to the screen resolutions and orientations of different hardware platforms (smartphones, tablets, laptops), can we imagine entire Sharing Economy platforms that offer different interfaces and interactional styles depending on, for example, availability of communication, data or backend services? Is the same level of sharing and trust possible given two different designs; one responsive and synchronously interactive, rich with pictures, emoticons and contemporary design; and the other simple, functional, no frills, perhaps distributed or not continuously available, even with a text-based interface? There are issues of trust, user experience, intelligibility, and expectation etc. at play here that may not be met by simple minimalist interfaces of a possible future 'limited' internet. Or are these issues context-specific and based on how severe the unmet needs are? on the social and geographical distance between participants? If the need is great enough, will people make do with fewer frills, simpler interfaces and be more patient when there are communication delays when resources are not available? These are all issues that need to be explored and are not well researched thus far.

It could be argued that some sharing initiatives are worth preserving even despite their costs. It would for example make sense to share resources locally but also-or especially - to share knowledge globally in a future of scarcity. Knowledge can refer to many different things, but one particular type of knowledge that could be highly relevant to share on a global scale is replicable concepts. A replicable concept well worth sharing is for example the very knowhow and tools needed to set up a (perhaps local) mediated sharing system.

In such a scenario, what is needed is 1) a code base for a minimalistic sharing system, 2) knowledge of what hardware, operating system and network connection is needed to get that code base to run, 3) know-how of how to set up such a system with the downloaded code base and finally 4) advice on how to set-up the supporting socio-technical system; recruiting participants and administrators and getting them to use the system. It would finally be exceedingly useful to also have access to insights into how to sustain and develop such a system over time 25. While the creation of code bases and support on practical aspects of setting up such systems might be perceived as outside the scope of Computing within Limits, research on such systems and 
practices should however be part of Computing within Limits much the same way that there is much practical work being done within open source software as well as research being conducted to analyse (and support) various aspects of these developments [34.

\section{PREPARING FOR A TRANSITION}

The profound changes to the economy and the society mentioned above can come about in a number of different ways. We will here elaborate on three different scenarios for how these shifts could come about.

- We could as a society become enamoured by and embrace sharing but without an awareness of the challenges posed by the Limits perspective and without an awareness of the possibility for rebound effects. The Sharing Economy would, in short, become incorporated in the current growth-oriented economic paradigm.

- We could as a society for a variety of reasons fall on "bad times" (due to ecological, social and/or economical reasons) and willingly or under duress be forced to adopt sharing solutions as a "survival tactic" of sorts, again without an awareness of the Limits perspective.

- We could prepare for the dual challenges of adapting to a Limits perspective by way of adopting selective Limits-compliant sharing solutions, including the development of the suitable (perhaps simple, resourcestingy, modular) technical infrastructure and rules for governing its usage.

The first two scenarios describe situations where we would not explicitly prepare for a transition to a world of various biophysical constraints, although some measures might still inadvertently be useful in such a transition. In the first scenario, it could be the case that wholehearted participation in the sharing economy, despite possibly leading to higher levels of resource consumption, might encourage the (inadvertent) development of values, attitudes, behaviors and abilities that would be useful in such a transition. The development of a preparedness to reevaluate the value of ownership, an increased generalised trust in fellow human beings ("strangers") etc. 27] could be compared to the argument that mediated sharing has the possibility of becoming a seed of a post-capitalist society $19,20,29$.

The second scenario also describes an inadvertent adaptation to a world of biophysical limits but this time due to the sheer need of learning to do more with less - since the alternative is to learn to do without. This scenario could be close to the current situation in Spain (and elsewhere) where "the lost generation" 4, 11] refers to those millions of youths who, due to the lingering effects of the 2008 economic crises, have failed to establish themselves on the labour market after graduation. Past research suggests that youths who graduate during a recession for various reasons suffer from the consequences of their unfortunate timing for a long time afterwards, for example because they will have to compete at a disadvantage with more recent graduates to find a job, because their initial salaries will be depressed etc. This suggests they will have to adopt various "survival tactics" of which participation in the sharing economy could be one. Due to these adaptations, they might-both despite and because of their unfortunate circumstances - be better prepared for a transition to a world of biophysical limitations.

The second scenario is also similar to Orlov's 23 description of ordinary Russians' development of a high level of "inadvertent collapse-preparedness" during the decades running up to the 1989 collapse of the Soviet Union. By making everyday life difficult and inefficient for many of its citizens, The Soviet Union had forced them to develop a resilience that inadvertently prepared them for a situation where many societal systems failed. By for example having a flawed system for producing and distributing food, many families had-out of dire need-access to small and very productive plots where they cultivated vegetables, and, this turned out to be very fortunate when the Soviet Union eventually collapsed. By living under duress, Soviet citizens had inadvertently prepared for the worst and Orlov speculates that if a more well-functioning society like the US would collapse, people would be much less prepared since everything would had worked comparatively smoothly right up to the collapse. Establishing suitable habits, behaviors and social networks to share resources could thus in both these two scenarios be seen as a way that people to inadvertently prepare for a transition to a future of biophysical limits.

The third scenario above is the "enlightened" option where we would consciously prepare for a future of limitations by developing and adopting suitable sharing solutions already in advance. We exhort the community to draw upon the origins and inventiveness that brought about the inception of the Internet in the first place, and in line with Tomlinson et. al., suggest we put effort into "the study, design, and development of sociotechnical systems in the abundant present for use in a future of scarcity" 38. This scenario corresponds to the Transition Town movement's conscious preparations for the twin challenges of peak oil and climate change 14. This scenario is in our opinion, the most desirable, but regrettably also the least probable of the three we propose.

\section{CONCLUDING REMARKS}

In this paper we have elaborated on the intersection between the Sharing Economy and Computing within Limits, and discussed where these two perspectives are aligned and where they are diverging. We have found several interesting research questions that could be explored in Computing within Limits so as to either make the Sharing Economy better aligned with a Limits perspective, or to make sure that we can easily share resources in a future of scarcity.

Despite not having acknowledged it explicitly, we have in fact referred to two different "scenarios" of a Limits-compliant Sharing Economy in the paper. One has large corporate intermediaries with global servers and the other has distributed, localized services. The former supports an extremely energy- and resource-efficient infrastructure for the global sharing of knowledge and replicable concepts, while the other relies on patchy, heterogeneous networks and local bottom-up skills, know-how and enthusiasm to for example download a code-base and set up a local system.

It should be noted that that our primary focus in this paper is resource throughput and ecological sustainability rather than social sustainability. There are many questions relating to the latter that could, but haven't been discussed here, for example what role the Sharing Economy could play in a shrinking economy and in relation to questions of (guar- 
anteed, fair or equal) access to resources, or, how tendencies of hoarding and monopolization of resources could be countered. We here refer to Heinberg [10] who states that "The purpose of the [sustainability principles] set forth here is not to describe conditions that would lead to a good or just society, merely to a society able to be maintained over time. It is not clear that perfect economic equality or a perfectly egalitarian system of decision-making is necessary to avert societal collapse". We analogously state that while social sustainability is desirable, it may strictly speaking not be necessary from the perspective of ecological sustainability, and, it is this particular perspective that we have adopted in this paper.

It is however evident that we need to further (re-)consider the fundamental structures of the most powerful tools at our disposal: the Internet and the world-wide web. It is unreasonable to assume the high levels of availability and service uptime we currently enjoy and that underpin web sites, social media hubs and communications platforms unproblematically will continue to exist in a future of limits.

It is also unclear today what such an "extreme Internet" scenario would look like. Here we can turn to the experience of colleagues already exploring "the edges of the Internet": researchers in ICT4D 6] and those who propose delay tolerant networking for deep space communication have already studied partially available network infrastructures where nodes are only fleetingly available, and draw upon intermittent power sources (e.g. from renewable energy sources). Even the margins of the mainstream Internet could provide inspiration. Hacker communities and the technologies that underpin "the dark web" can illustrate how out of necessity, services can be created that do not assume a fixed or stable mapping between content and IP addresses, and how to do without "normal" Internet services such as domain name resolvers. Hence it is difficult to discuss the future of mediated sharing when we have few plausible visions of the future of computing in general, and one of our main conclusions in this paper is that the research community needs to develop these scenarios, even though the major part of them will never come true.

\section{ACKNOWLEDGMENTS}

We would like to thank Åsa Minoz for her thoughtful comments on this paper, as well as the reviewers' comments on an earlier version. We would also like to thank Airi Lampinen and Karin Bradley for previous discussions on the sharing economy.

\section{REFERENCES}

[1] B. Balaram. Fair share - reclaiming power in the sharing economy. Royal Society for the encouragement of Arts, Manufactures and Commerce. . Available at: https://www.thersa.org/discover/publications-andarticles/reports/fair-share-reclaiming-power-in-thesharing-economy/, 2016.

[2] R. Belk. Why not share rather than own? The Annals of the American Academy of Political and Social Science, 611(1):126-140, 2007.

[3] V. M. Bellotti, S. Cambridge, K. Hoy, P. C. Shih, L. R. Handalian, K. Han, and J. M. Carroll. Towards community-centered support for peer-to-peer service exchange: rethinking the timebanking metaphor. In Proceedings of the SIGCHI Conference on Human Factors in Computing Systems, pages 2975-2984. ACM, 2014.

[4] J. Blitzer. Spain's lost generation: What do you do when half your country's youth is unemployed? New Republic. Available at: https://newrepublic.com/article/103708/spainunemployment-youth-euro, May 2012.

[5] R. Botsman and R. Rogers. What's mine is yours: how collaborative consumption is changing the way we live. Collins London, 2011.

[6] J. Chen. Computing within limits and ICTD. First Monday, 20(8), 2015.

[7] E. M. A. Foundation. Growth within: A circular economy vision for a competitive europe. available at: https://www.ellenmacarthurfoundation.org/publications/growthwithin-a-circular-economy-vision-for-a-competitiveeurope. Ellen MacArthur Foundation, 2015.

[8] S. P. Fraiberger and A. Sundararajan. Peer-to-peer rental markets in the sharing economy. NYU Stern School of Business Research Paper, 2015.

[9] X. Gui and B. Nardi. Foster the "mores", counter the "limits". First Monday, 20(8), 2015.

[10] R. Heinberg and D. Lerch. What is sustainability? The Post Carbon Reader, pages 11-19, 2010.

[11] J. Henley. Young, qualified and jobless: plight of europe's best-educated generation. The Guardian. Available at: http://www.theguardian.com/world/2013/jul/01/joblesseurope-young-qualified, July 2013.

[12] C. Hess and E. Ostrom. A framework for analyzing the knowledge commons: a chapter from understanding knowledge as a commons: from theory to practice. 2005 .

[13] L. M. Hilty. Why energy efficiency is not sufficient-some remarks on "green by it". In EnviroInfo, pages 13-20, 2012.

[14] R. Hopkins et al. The transition handbook. From Oil Dependency to Local Resilience, Cambridge, 2008.

[15] L.-S. Huang. \#wewashing: When "sharing" is renting and "community" is a commodity. Huffington Post. Available at: http://www.huffingtonpost.com/leeseanhuang/wewashing-when-sharing-is_b_6879018.html, 2015.

[16] W. S. Jevons. The coal question: an inquiry concerning the progress of the nation, and the probable exhaustion of our coal-mines. Macmillan, 1906.

[17] D. MacKay. Sustainable Energy-without the hot air. UIT Cambridge, 2008.

[18] C. J. Martin. The sharing economy: A pathway to sustainability or a nightmarish form of neoliberal capitalism? Ecological Economics, 121:149-159, 2016.

[19] P. Mason. Postcapitalism: A Guide to Our Future. Macmillan, 2016.

[20] D. McLaren and J. Agyeman. Sharing Cities: A Case for Truly Smart and Sustainable Cities. MIT Press, 2015 . 
[21] T. Meelen and K. Frenken. Stop saying über is part of the sharing economy. Fast Company. Available at: http://www.fastcoexist.com/3040863/stop-saying-uberis-part-of-the-sharing-economy, January 2015.

[22] M. P. Mills. The cloud begins with coal. Digital Power Group. Available at: http://www. tech-pundit. com/wpcontent/uploads/2013/07/Cloud_Begins_With_Coal.pdf, 2013.

[23] D. Orlov. Reinventing collapse: The Soviet example and American prospects. New Society Publishers, 2008.

[24] D. Owen. The conundrum: How scientific innovation, increased efficiency, and good intentions can make our energy and climate problems worse. Riverhead Books New York, NY, 2012.

[25] D. Pargman. Code begets community: On social and technical aspects of managing a virtual community. 2000.

[26] D. J. Patterson. Haitian resiliency: A case study in intermittent infrastructure. First Monday, 20(8), 2015.

[27] R. D. Putnam. The prosperous community. The american prospect, 4(13):35-42, 1993.

[28] R. D. Putnam. Bowling alone: America's declining social capital. Journal of democracy, 6(1):65-78, 1995.

[29] J. Rifkin. The zero marginal cost society: the internet of things, the collaborative commons, and the eclipse of capitalism. Macmillan, 2014.

[30] M. B. Rivera, C. Håkansson, A. Svenfelt, and G. Finnveden. Including second order effects in environmental assessments of ict. Environmental Modelling \& Software, 56:105-115, 2014.
[31] E. M. Rogers. Elements of diffusion. Diffusion of innovations, 5:1-38, 2003.

[32] J. Schor. Debating the sharing economy. Great transition initiative, 2014.

[33] C. Shirky. Here comes everybody: How change happens when people come together. Penguin UK, 2009.

[34] M. S. Silberman. Information systems for the age of consequences. First Monday, 20(8), 2015.

[35] R. Solnit. A paradise built in hell: The extraordinary communities that arise in disaster. Penguin, 2010.

[36] G. Standing. The precariat: The new dangerous class. A\&C Black, 2011.

[37] S. Subramanya, Z. Mustafa, D. Irwin, and P. Shenoy. Energy-agility: A new grid-centric metric for evaluating system performance. In First International Workshop on Computing within Limits, 2015.

[38] B. Tomlinson, M. Silberman, D. Patterson, Y. Pan, and E. Blevis. Collapse informatics: augmenting the sustainability \& ICT4D discourse in HCI. In Proceedings of the SIGCHI Conference on Human Factors in Computing Systems, pages 655-664. ACM, 2012.

[39] A. Wijkman and K. Skånberg. The circular economy and benefits for society swedish case study shows jobs and climate as clear winners. An interim report by the Club of Rome with support from the MAVA

Foundation and the Swedish Association of Recycling Industries. Available at:

http://www.clubofrome.org/a-new-club-of-rome-studyon-the-circular-economy-and-benefits-for-society/, 2015 . 